\title{
Adoption of International Accounting Standards in Emerging Countries: A Cultural Perspective
}

\author{
Rabeb Riahi
}

\section{ABSTRACT}

\begin{abstract}
The article aims at studying the adaptability of international accounting standards to emerging countries. We use a cultural approach based on the accounting subculture (Gray, 1988) that highlights the relationship between cultural dimensions (power distance, uncertainty avoidance, individualism vs. collectivism, masculinity vs. femininity), and accounting values (professionalism vs. statutory control, uniformity vs. flexibility, conservatism vs. optimism and discretion vs. transparency). The cultural approach reveals the magnitude of adaptability of international accounting standards to emerging countries by considering the Tunisian example. Thus, we first identify the culture of the studied context by a questionnaire including the evolution tendency of this context. Secondly, we identify the cultural context required to adopt the international accounting referent. Our results reveal that the Tunisian cultural context is slightly different from that required for the adoption of the international referent. However, we have observed a process of convergence towards it.
\end{abstract}

Keywords: Cultural dimensions, cultural evolution, accounting values, international accounting standards, Tunisian cultural context.

\section{INTRODUCTION}

The globalization of the economy and the growth of multinational enterprises had led to the diversity of accounting systems and begun to create problems of financial information's comparability. So that, different accounting systems began to create problems to users and different interpretations began to be given for the same events and transactions. This heterogeneity in accounting practices is considered to be one of the most important factors in the inefficiency of financial markets and causes the phenomenon of creative accounting (Obert, 2004). The International Accounting Standards Board (IASB) has developed in the context of international accounting harmonization a set of accounting standards recognized worldwide whose objective is to work towards the convergence of national and international accounting standards for high-quality solutions. The question of convergence has been the subject of a large number of accounting research studies. This issue seemed to be, partially resolved through the increasing official recognition of international accounting standards/international financial reporting standards (IAS/IFRS). So, the adoption of IAS/IFRS standards seems to be a relatively easy outcome for companies belonging to developed economies and/or listed on sophisticated markets. But, what about IAS/IFRS adaptability in less developed companies belonging to emerging economies, where markets are less sophisticated and financial statements are intended for fewer numbers of users? In emerging countries, many factors are likely to work against the convergence of accounting practices with IAS/IFRS standards. McGee and Preobragenskaya (2003) argue that the insufficient number of
Submitted : December 16, 2021

Published : January 10, 2022

ISSN: 2507-1076

DOI: $10.24018 /$ ejbmr.2022.7.1.1205

Rabeb Riahi*

URRED, Higher Institute of Management,

University of Gabès, Tunisia.

(e-mail: rabebriahi@yahoo.fr) accountants qualified to manage an international accounting system is an obstacle to the practice of international standards. While many accountants of big companies belonging to emerging countries acknowledge that the purpose of financial statements is to provide relevant information to investors, this idea remains unnoticed by accountants in smaller companies. Hope (2003) emphasizes the "practices" factor. He argues that the recognition of IAS/IFRS does not imply a decrease in differences between countries. Kothari (2001) explains that the quality of financial reporting is a function not only of the quality of the standards but also of the practice of these standards by companies. Hence, even the highest quality standards will be irrelevant if there is no practice (Hope, 2003). Moreover, several researchers linked accounting practices of a given country to its national culture, including (see Riahi, 2017; Ding et al., 2005; Baskerville, 2003; Doupnik and Salter, 1995; Perera, 1994). They used both Hofstede's (1980) cultural dimensions and Gray's (1988) accounting values to determine the relationship of national culture with the accounting practices of the relevant country. In this perspective, the factors influencing the accounting practices are facts derived from the culture of a given country. Indeed, to determine the extent of the adaptability of the international standards within a given country, we propose to consider the culture of this country and its evolution.

The Tunisian context provides a relevant example to the study of emerging countries. In fact, following economic changes and the establishment of a market economy, Tunisia was constrained to set up a new accounting system that better responded to the information needs of the increasingly diversified users of financial statements. This transition of the 
Tunisian accounting culture from a general plan of accounts to an accounting system with a conceptual framework has given rise to several questions. Indeed, by comparing the Tunisian accounting system with international standards, we notice that the Tunisian conceptual framework is, in many respects, very similar to the IASB's framework. In our opinion, the fact that the Tunisian Accounting System is strongly inspired by the international is a real advantage because its adoption and recognition are a key means of promoting the adoption of international standards in Tunisia. Mabkhout (2006) argues that in Tunisia, the new generation of accountants has come to recognize the rules of measurement and presentation recommended by the Enterprise Accounting System.

The study aims to identify the extent of the international accounting standards adaptability to the cultural context of emerging countries. Thus, we first provide the theoretical background (section II). Then, we review relevant literature and develop research hypotheses (section III) and describe research methodology (section IV). We present results and discussions in section $\mathrm{V}$ and give conclusions and future perspectives in section VI.

\section{THEORETICAL BACKGROUND: THE ACCOUNTING SUBCULTURE}

Accounting is a discipline that provides individuals' judgments when applying accounting principles. This human effect influencing accounting practices is due to culture. Thus, cultural relativism is often recommended when studying accounting practices' diversity (Riahi, 2017; Gray, 1988; Riahi-Belkaoui, 1995; Doupnik and Salter, 1995; Hofstede, 2001). In the first hand, cultural relativism theory means that differences in attitudes and beliefs are guided by cultural diversity. In the other hand, accounting subculture theory (Gray, 988) suggests that accounting practices are affected by societal values and help to reinforce these values. Thus, accountants' value systems are guided by their social values regarding work-related values. Accounting values evolve and vary according to the environment and reflect and reinforce societal values. Thus, the central hypothesis developed by Gray (1988) is that, through different societal values, external influences and the environment help to establish different accounting systems and values. The accounting subculture (Gray, 1988) includes only four cultural dimensions which are power distance, uncertainty avoidance, individualism vs. collectivism, masculinity vs. femininity.

\section{A. What is National Culture?}

Many studies try to define national culture. Sørnes et al. (2004) have identified almost 400. Most of these definitions state that the cultural environment influences the values of the members of any society.

The first definition of culture is by Taylor ${ }^{1 \cdot}$ He defines it as any complex that includes knowledge, beliefs, art, morals, law, customs, and other abilities or habits acquired by man as a member of society (Taylor, 1871). Nevertheless, Hofstede

1 Taylor (1832-1917), a British anthropologist who is considered by several researchers as the founder of ethnology (Pesqueux, 2000).
$(1980,2001)$ is considered to be the first researcher to demonstrate a fairly modern definition of culture adequate for management research (Pesqueux, 2000). He defines culture as "the collective programming of the mind; it manifests itself not only in values but in other more specific qualities: in symbols, heroes and rituals" (Hofstede, 2001, p.1). Hofstede's study was based on an interview with IBM employees in 66 countries worldwide. He developed a model that identifies 6 cultural dimensions, namely power distance, uncertainty avoidance, individualism vs. collectivism, masculinity vs. femininity, long-term vs. short-term orientation, and Indulgence vs. restraint (Hofstede, 2010). By using this model, cultural differences and their consequences across countries can be described in more detail.

Power distance means the extent to which subordinates accept that power in institutions and organizations is unevenly distributed. It is measured by the perception that the subordinate has of the leader's power. The subordinate accepts this power more or less depending on the culture. Uncertainty avoidance is the extent to which individuals feel threatened by unknown and unusual situations. In other words, it is how members of society approach to risk. This is expressed by a need for formality, predictability, and clear roles. Individualism (vs. collectivism) means the degree of independence and freedom that members of a society can demand. In individualistic societies, individuals only care about themselves and their immediate family, whereas in communal societies, individuals act in cohesive groups Masculinity (vs. femininity) means the preoccupation with the values of success and possession. Conversely, feminine behavior favors mutual support. In masculine societies, men are authoritarian, tough, and only concerned with material success, while women are more modest, affectionate, and concerned with the quality of life. Long-term vs. short-term orientation the long-term orientation promotes values associated with the future such as a sense of economy and savings, classification of relationships by status, respect for this order, perseverance... Conversely, the short-term orientation favors values associated with the present such as individual preference for rigor and personal stability, protection of personal image, and respect for traditions. Indulgence vs. restraint opposes societies able to satisfy the individuals' personal needs and desires to societies governed by strict social norms and advocating the regulation of the impulses of its members.

\section{B. Accounting Values}

Gray's (1988) model identifies accounting practices through four accounting values which are professionalism vs. statutory control, uniformity vs. flexibility, conservatism vs. optimism, and discretion vs. transparency.

Professionalism vs. statutory control distinguishes countries where professional accountants have some latitude to exercise professional judgment and maintain professional self-regulation, versus countries that aligned only with recommendations imposed by government agencies. Uniformity vs. flexibility opposes flexible countries with uniform countries accounting practices. Conservatism vs. optimism opposes conservative countries, which are cautious 
about uncertainty to optimistic countries, which take more risks in these same circumstances. Discretion vs. transparency distinguishes countries that prefer confidentiality and restriction of business information to those directly involved in management and financing, versus countries that adopt an approach of transparency, openness, and public disclosure.

\section{LITERATURE REVIEW AND HYPOTHESES DEVELOPMENT}

Gray (1988) argues that uniformity may be closely related to uncertainty avoidance. The preference for uniformity is in alignment with the preference for strong uncertainty avoidance and collectivism. Ding et al. (2005) add that a high degree of uniformity would be expected to be associated with high power distance. They reversed Gray's (1988) to conclude that inconsistency will be related to a low level of uncertainty avoidance and power distance and high levels of individualism.

A high level of accounting flexibility seems to be more accepted in companies where power distance is not significant. In such societies, equal rights are valued. Individuals feel less threatened and more confident (Chanchani and MacGregor, 1999). Gray (1988) adds that a low level of masculinity is associated with a high level of conservatism.

International standards are recognized by a preference for fairly extensive disclosure, an approach of transparency (less discretion), and less conservatism (Ball et al., 2000). Gray (1988) associated the last two dimensions (less conservatism and less discretion) with less uncertainty avoidance. Hence, compliance with international standards (which impose more uniformity and less discretion) would be linked to less uncertainty avoidance. This idea has been supported by other authors, including Ding et al. (2005) and Salter and Niswander (1995).

Similarly, Robinson and Venieris (1996) argue that a high level of professionalism is linked to individualistic countries, less prone to uncertainty, and whose citizens are less distant from power. Moreover, a low level of individualism and a high level of uniformity are associated with more uncertainty avoidance and power distance. Finally, a low level of individualism and masculinity and a high level of discretion are associated with more uncertainty avoidance and power distance.

In Gray's model (1988), masculinity and individualism are two closely related values that correlate behaviors. Hence, we have attributed to masculinity the same correlation of individualism with professionalism and uniformity. Also, the same correlation between masculinity and conservatism was attributed to individualism.

We have also noticed that the accounting values conservatism and discretion adopt the same correlation behaviors with Hofstede's (1980) cultural values. Hence, we have attributed a positive correlation between conservatism and power distance. The same correlation sign was attributed to the relationship between discretion and power distance. Moreover, a low level of masculinity is linked to a high level of conservatism and discretion. Based on the above implications, we have been able to develop the following hypotheses. Since IAS/IFRS referent is characterized by uniformity, optimism, professionalism, and transparency, we hypothesize that:

H1. A low level of power distance is associated with accounting practices that diverge from international standards.

H2. A low level of individualism is associated with accounting practices that diverge from international standards.

H3. A high level the uncertainty avoidance is associated with accounting practices that diverge from international standards.

H4. A low level of masculinity is associated with accounting practices that diverge from international standards.

\section{A. The Conceptual Framework}

Based on hypotheses developed, we suggest the following framework providing the correlation signs between Hofstede's cultural dimensions and the cultural context needed the adoption of the international referent.

TABLE I. THE CONCEPTUAL FRAMEWORK

\begin{tabular}{lcc}
$\begin{array}{l}\text { Convergence } \\
\text { with intemational } \\
\text { standards }\end{array}$ & $\begin{array}{l}\text { Divergence from } \\
\text { intemational } \\
\text { standards }\end{array}$ \\
\hline Correlation & Cultural dimensions & Correlation \\
\hline+ & Powver distance (H1) & - \\
+ & Individualism (H2) & - \\
- & Uncertainty avoidance (H3) & + \\
+ & Masculnity $(\mathrm{H} 4)$ & - \\
\hline
\end{tabular}

\section{B. The Tunisian Example}

The studies on Tunisian national culture show some slight differences. This may be due to the diversity of Tunisian cultural sources. Indeed, Tunisia has been affected by a diversity of national cultures; Punic, Arab, African, European, and Muslim cultures and the influence of the successive dynasties that rule the country. While ArabMuslim culture is characterized by a high degree of power distance and low uncertainty avoidance, European culture is characterized by moderate power distance and high uncertainty avoidance. The nuance of the results may also be due to the evolution of the Tunisian context. We think that cultural dimensions must be identified with consideration to the evolution of the Tunisian context. Tunisia has undergone economic changes aimed at establishing a market economy. Indeed, it has signed the GATT agreements, created a free trade zone with the European Union, the liberalization of interest and exchange rates, the convertibility, and the dynamization of the stock market. The reform of the Tunisian accounting system was implemented in response to the complaints of several professionals and academics. Indeed, there was a necessity to meet the new requirements of information needs. The Accounting System has been the subject of several studies. Indeed, it was developed as a result of several surveys on accounting practices and the positioning of the previous account plan with the international and American standards developed by the Accounting Standards Committee of the Stock Exchange, Ernst \& Young, and Coopers \& Lybrand (Price Waterhouse, 2006). As consequence, the old accounting system no longer met the 
requirements of the increasingly diverse information needs of financial statements users. This is in addition to the concern for a harmonization of the Tunisian accounting system with the IASB's referent (Chouchane, 2005).

The framework of Doupnik and Salter (1995) may explain the evolution of the Tunisian cultural context. Indeed, the transition to a market economy, the GATT agreement, and the concern for accounting harmonization are intruding events. Subsequently, the transition from a planned to a market economy and all the intrusions were followed by an accounting reform. Indeed, there was a transition from an account plan to an accounting system with a conceptual framework and accounting standards inspired by international standards. The Tunisian accounting system has, therefore, interacted with the international accounting system to develop a response to these intrusions. This transition is the result of the interactions generated (Chouchane, 2005).

The Tunisian cultural context has not been the subject of several empirical studies. Hofstede's study (1980) placed Tunisia among the Maghreb countries. The conclusions drawn by the author suggest that Tunisian culture is characterized by a very high-power distance, a low uncertainty avoidance, a community spirit, and a tendency towards femininity. Ben Fadhel's (1992) study borrowed Hofstede's (1980) approach based firstly on the collective consciousness manifested through Tunisian proverbs, and secondly on a questionnaire. The results show that the Tunisian context is characterized by a high-power distance, a low uncertainty avoidance, a tendency towards collectivism, and a certain balance between masculinity and femininity. Similarly, Soyah and Magroun (2004) have pointed out that the masculine or feminine tendency cannot be identified in Tunisia.

\section{RESEARCH METHODOLOGY}

Our methodology aims firstly to identify the Tunisian cultural dimensions and their evolution, and then, to study the adaptability of international standards in the Tunisian context. The next step aims to place the Tunisian cultural context in the developed grid relating to the extent of convergence with the international accounting standards. So that, the dimensions identified will be confronted to the cultural dimensions that are essential to the adoption of international standards. The previous research doesn't show relevant conclusions because they did not reveal harmonious results.

The unobservable nature of national culture provides problems linked to its measurement. Previous studies identify culture either through Hofstede indices, through questionnaires or through SEM method (Riahi et al., 2020, Riahi and Hamouda, 2018). Since our study includes a single context and considers cultural changes, the most reliable methodology remains the questionnaire. This questionnaire aims at identifying the cultural dimensions included in the accounting subculture in the studied context, namely, power distance, uncertainty avoidance, individualism vs. collectivism, masculinity vs. femininity. The questionnaire is addressed to a varied Tunisian population (different genders, ages, living standards, and education levels). Indeed, we seek to differentiate the population targeted to avoid the influence of a single variable and to identify the evolution of Tunisian culture if any exist.

Despite the criticism of Hofstede's (1980) dimensions in the literature, it stills the most relevant model for measuring cultural proximities and remains the most widely used in accounting and psychology researches (Ding et al., 2005). Sondergaard (1994) and Schwartz and Sagiv (1995) argue that confirmations contrary to Hofstede's represent a minority of the researches in the study of national culture. Similarly, the relevance of Hofstede's (1980) dimensions has been verified by several research studies such as Riahi et al. (2020), Riahi and Hamouda (2018), Shwartz (1992), Trompenaars (1993), "the Chinese culture connection" (1987). In addition, several studies have shown that the cultural dimensions of Hofstede (1980) have not lost their validity (Barkema and Vermeulen, 1997; Fernandez et al., 1997). Indeed, Hofstede's (1980) model has served as the basis for several other studies, including Gray's (1988) model used in our research.

According to previous research such as Ding et al. (2005), the international framework is characterized by uniformity, optimism, professionalism, and transparency. The developed grid presenting the effect of cultural dimensions on the extent of convergence with the international frame of reference assumes that this framework is, normally, easily adaptable in a cultural environment characterized by low power distance, low uncertainty avoidance, and a high degree of individualism and masculinity.

\begin{tabular}{ccccc}
\multicolumn{5}{c}{ TABLE II. THE CULTURAL CONTEXT NEEDED TO IAS/IFRS STANDARDS } \\
ADAPTABILITY
\end{tabular}

Our initial sample consisted of 200 participants surveyed during 2006, and who were asked to assess their level of agreement on some life values by answering a set of "yes" or "no" questions. However, given the shortcomings and omitted answers, we were able to retain 113 responses $(56 \%$ of the original target). The criteria retained for the individuals in our sample are gender, age, level of education, and income level.

The criterion "gender" was used to classify the population, given that Hofstede's cultural dimensions include masculinity/femininity. In other words, the culture may differ depending on whether one is a woman or a man. In our opinion, the "age" criterion is significant as the country would have experienced the evolution of the cultural context. This evolution will be identified in the sense that the emerging population would present a different culture from the rest of the population. In our sample, we distinguished between three age categories: "between 20 and 35", "36-55 years" and "56 years and over".

The criterion "level of education" was retained because it has a significant effect on the culture of a country. Indeed, a population composed of highly educated individuals may differ greatly from one with a moderately educated population. Thus, our sample was broken down into 'primary 
level', 'secondary level' and 'university level'.

The criterion "level of income" has been included in our study because the living standard is likely to shape the culture of a country. Hofstede (1980) argues that the living standard has a considerable influence on the cultural dimensions of 'individualism' and 'masculinity'. We have then disaggregated our sample as follows: "less than 400 TD", "between 400 and 800 DT", "between 800 and 1200 DT", and "1200 DT and more".

\section{RESULTS AND DISCUSSIONS}

\section{A. The Tunisian Culture}

The results of our questionnaire confirm, on the one hand, a significant degree of power distance. Indeed, $82 \%$ of the respondents to our questionnaire admit that our environment is characterized by social inequality. $11 \%$ of these respondents affirm that this inequality is justified and perceive the legitimacy of the concentration of power as long as knowledge is unequal. The rest of the population accepts that inequality in knowledge does not justify inequality in power. Overall, power distance seems to exist in the Tunisian context without being fully accepted. This is consistent with the results of Soyah and Magroun (2004). Among the claimants of the first finding, $63 \%$ affirm that social inequality is still increasing. Only $37 \%$ perceive that the power distance is becoming less pronounced. The perception of a high-power distance does not seem to exist in the perception of any particular category in our sample. Indeed, this perception is equally distributed across the different categories interviewed. This means that the "power distance" dimension has not changed in the Tunisian context.

On the other hand, the results of our questionnaire show that the Tunisian population tends to take the risk. Indeed, $70 \%$ of our samples say that they are not stressed about their future. Most of the claimants of this finding belong to the categories "36-55 years old" and "56 years and older". This is normally due to the usual fears of individuals in the "20-35" category, whom majority do not have yet achieved job stability. The results also showed that the higher the level of educational attainment, the lower the uncertainty avoidance. This can be justified by the confidence that the individual can have concerned the future by being well educated. In addition, $91 \%$ of respondents state that religion helps to confront the uncertainties of the environment. Overall, the level of uncertainty avoidance seems to be low for the selected Tunisian population.

The "individualism/collectivism" dimension shows a nonegalitarian dispersion between the categories of the surveyed population. Indeed, the "56 and over" category (91\%) shows a significant degree of collectivism. The category "between 36 and 55" (75\%) shows a lower degree of individualism than the "56 and over" category and more than the "20-35" category $(72 \%)$. This shows that the Tunisian culture provides a community spirit, but this criterion tends to be less important from one generation to the next. This dimension also shows a difference in category (male/female). Indeed, women favor group spirit $(65 \%)$ while men have individualistic tendencies (35\%). Similarly, we have noticed that the individualistic or communitarian spirit differs according to the standard of living. Indeed, in the one hand, the individualistic culture is more common among the higherincome groups. On the other hand, the level of education shows a negative correlation with the individualism dimension. Indeed, we have noticed that the higher the level of education is, the more community-minded the individuals belonging to this category.

Finally, we have noticed an unequal distribution of the percentages of the "masculinity/femininity" dimension across the categories studied. We found that the Tunisian culture is rather feminine $(73 \%)$ as the individuals interviewed accept to express their feelings and refuse sexual discrimination. However, this trend seems to be diminishing further, as we have noticed that masculinity is increasingly present in the categories "between 20 and 35 years" and "1200 TD and over". In addition, women have shown a greater degree of femininity than men (49\% vs. $24 \%)$. In short, the Tunisian context is characterized by a female culture that tends to be increasingly diminished.

In summary, we may conclude that the Tunisian context is characterized by:

A high power distance appears to be stable across the categories of the surveyed population. Indeed, this perception seems to already exist and remains present in the minds of the emerging population;

Low uncertainty avoidance: this dimension was influenced by two main criteria, namely age and education. criteria, namely, age and education. On the one hand, this dimension is prominent among the mature, and on the other hand, among the highly educated individuals. Although this dimension was low for the youth category, we do not allow ourselves to generalize it to the population as this result may be attributable to other factors such as job stability;

Individualism/Collectivism: The Tunisian culture is characterized by a community spirit with an increasing tendency towards individualism. Indeed, this dimension varies according to the criteria of gender, age, level of education, and income level.

Masculinity/femininity: our study revealed the existence of feminine culture in Tunisian society but which tends to diminish from one generation to another. Usunier (2003) argues that the trend towards masculinity is synonymous with openness to the outside world.

Adaptability of the international accounting referent

The following table provides the cultural dimensions of the Tunisian context compared to those that characterize the adoption of international standards.

TABLE III. TUNiSIAN CULTURAL CONTEXT vS. THE CUltural CONTEXT NEEDED TO IAS/IFRS STANDARDS ADAPTABILITY

\begin{tabular}{ccccc}
\hline \multicolumn{5}{c}{ NEEDED TO IAS/IFRS STANDARDS ADAPTABILITY } \\
& $\begin{array}{c}\text { Power } \\
\text { distance }\end{array}$ & $\begin{array}{c}\text { Uncertainty } \\
\text { avoidance }\end{array}$ & Individualism & Masculinity \\
\hline $\begin{array}{c}\text { The international } \\
\text { frame of reference } \\
\text { The Tunisian } \\
\text { context }\end{array}$ & + & - & + & + \\
\hline
\end{tabular}

* A tendency towards individualism.

** A tendency towards masculinity.

Findings show that the Tunisian context differs from the context which is necessary for the adoption of the international benchmark in two dimensions. However, the new trends observed in our study confirm that the Tunisian context tends to open up to the outside and is evolving 
towards a culture which is gradually converging towards that needed for the adoption of the international referent.

The grid developed shows that Tunisia has adopted an accounting system inspired by the international benchmark not only for the sole purpose of harmonization, but also because the Tunisian cultural dimensions (and consequently, the accounting values) are located on the axis of convergence of the cultural context necessary for the adoption of the international referent.

\section{CONClusions AND Future PERSPECTIVES}

The study aimed to identify the relationship between national culture and accounting practices and, to develop a conceptual framework for the adaptability of the emerging cultural context to the international accounting standards by considering the Tunisian example. The adoption of the Tunisian Accounting System (1997) inspired by AngloSaxon has raised questions about its compatibility with the Tunisian cultural context. This new accounting system was implemented as a result of certain decisions, notably the opening up of the economy and the adherence to globalization mechanisms. Some research claims that the accounting system is not compatible with the country's culture since it is rules for large companies operating in sophisticated markets.

The international accounting referent is characterized according to previous researches by high power distance, low uncertainty avoidance, individualistic and masculine behavior. In our developed grid, the Tunisian cultural context is on the axis that tends to converge towards the international cultural context. Indeed, the findings show that the Tunisian cultural context is a priori not very different from which necessary for the adoption of the international accounting referent, but it tends to be closer to it and to open up more to the outside world. Our results are in line with some previous researches. Mabkhout (2006) argues that the rules of recognition, measurement, and presentation mentioned by the Tunisian Accounting System (1996) have marked the minds of the new generation of Tunisian accountants. However, an update to follow the new developments under IFRS would be instrumental in keeping an up-to-date accounting system (Mabkhout, 2006).

Our research has the merit, on the one hand of being an attempt to theorize the relationship between national culture and adaptability to international accounting referent, a subject that has recently gained interest among some accounting researchers. On the other hand, we studied the evolution of the Tunisian cultural context, which has been approached in most research from a static angle. Nevertheless, our research may be subject to certain limitations. Indeed, the number of individuals in our sample may be quite small if we consider the total number of individuals in the Tunisian population. Although we have tried to address this limitation by choosing a diverse population, we do not claim the impossibility of some omitted variables. Therefore, future research may include a larger number of individuals, and with proposed questionnaire responses indicating the level of agreement or disagreement. Likewise, a study on the relationship between corporate culture and accounting practices could complement current research.

\section{REFERENCES}

Ball, R., Kothari, S. P., \& Robin, A. (2000). The effect of international institutional factors on properties of accounting earnings. Journal of Accounting and Economics, 29(October), 1-51.

Barkema, H. G, \& Vermeulen, F. (1997). What differences in the cultural backgrounds of partners are detrimental for international joint venture? Journal of International Business Studies, 28(4), 845-864

Baskerville, R. F. (2003) Hofstede never studied culture. Accounting, Organizations and Society, 28(1), 1-14.

Ben Fadhel, A. (1992). La dynamique séquentielle culture-gestion fondements théoriques et analyse empirique du cas tunisien. [Doctoral dissertation, University of Nice, IAE], FDSE.

Chanchani, S., \& McGregor, A. (1999). A synthesis of cultural studies in accounting, Journal of Accounting Literature, 18, 1-30.

Chinese Culture Connexion. (1987). Chinese values and the search for culture-free dimensions of culture. Journal of Cross-cultural Psychology, 18, 143-164.

Chouchane, B. (2005). Evolution culturelle comptable ou Acculturation? Cas de la Tunisie, 4ème Journée : Gestion des Ressources Humaines et Contrôle de Gestion "Comptabilité, Contrôle et Audit Sociaux».

Ding, Y., Jeanjean, T., Stolowy, T. (2005). Why do national GAAP differ from IAS? the role of culture. The International Journal of Accounting, (40), 325-350.

Doupnik, T. S., \& Salter, S. B. (1995). External environment, culture and accounting practices: a preliminary test of a general model of international accounting development. The International Journal of Accounting, 30, 189-207.

Fernandez, D. R., Carlson, D. S., Stepina, L. P., \& Nicholson, J. D. (1997). "Hofstede's country classification 25 years later", Journal of Social Psychology, 137, 43-54.

Gray, S. J. (1988). Towards a theory of culture influence on the development of accounting systems internationally. Abacus, 24(1), 1-15.

Hofstede, G., Hofstede, G. J., \& Minkov, M. (2010). Cultures and Organizations: Software of the Mind. London: McGraw-Hill.

Hofstede, G. (2001). Culture's Consequences: Comparing Values, Behaviors, Institutions and Organizations Across Nations, 2nd ed. Thousand Oaks, Sage Publications.

Hofstede, G. (1980). Culture's Consequences: International Differences in Work Related Value. Beverly Hills, Sage Publications.

Hope, O. K. (2003). Disclosure practices, enforcement of accounting standards and analysts' forecast accuracy: An international study. Journal of Accounting Research, 41(2), 235-272.

Kothari, S. P. (2001). Capital Markets Research in Accounting. Journal of Accounting and Economics, 31, 105-231.

Mabkhout, A. (2006). Vers une indispensable reconversion du Référentiel Comptable Tunisien aux nouvelles normes internationales IFRS. L'Economiste. février.

McGee, R. W., \& Preobragenskaya, G. G. (2003). Problems of Implementing International Accounting Standards in a Transition Economy: A Case Study of Russia, Institutional \& Transition Economics eJournal.

Obert, R. (2004). Pratiques des normes IAS/IFRS. 2nd ed, Dunod.

Perera, H. (1994). Culture and international accounting: Some thoughts on research issues and prospects. Advanced in International Accounting, 7, 267-285.

Pesqueux, Y. (2000). Culturalisme et mondialisation des entreprises. Cahier du Lipsor.

Price Waterhouse Coopers. (2006). Similarités et Divergences, une comparaison entre les Normes Comptables Internationales (IFRS), Américaines (US GAAP) et Tunisiennes (NCT). Janvier.

Riahi, R., Hamouda, F. \&, Henchiri, J. (2020). Measuring cultural dimensions for cross-cultural management: corporate governance outlook. Corporate Ownership and Control, 17(2), 157-164

Riahi, R., Hamouda, F. (2018). Cultural dimensions origins: measures for power distance and uncertainty avoidance. Global Journal of management and business research, 18(8), 41-47.

Riahi, R. (2017). Pratique de la gestion des résultats et culture nationale. Quel lien?. Journal of Academic Finance, 8(2), 77-97.

Riahi-Belkaoui, A. (1995). The Cultural Shaping of Accounting. Quorum Books, Westport.

Salter, S. B, \& Niswander, F. (1995). Cultural influence on the development of accounting systems internationally: a test of Gray's [1988] theory. Journal of International Business Studies, 26(2), 379-397.

Schwartz, S. H, \& Sagiv, L. (1995). Identifying culture-specificities in the cintent and structure of values. Journal of cross-cultural psychology, 26(1), 92-116.

Schwartz, S. H. (1992). Universals in the content and structure of values: theoretical advances and empirical tests in 20 countries. in Zama (Ed.), Advances in Experimental Social Psychology, NY academic press: 166. 
Sondergaard, M. (1994). Research note: Hofstede's consequences: A study of reviews, citations and replications. Organizational Studies, 15(3), $447-456$.

Sørnes, J. O., Stephens, K. K., Sætre, A. S., \& Browning, L. D. (2004). The reflexivity between ICTs and business culture: Applying Hofstede's theory to compare Norway and the United States. Informing Science Journal, 7, 1-30.

Soyah, T., Magroun, W. (2004). Influence du contexte culturel tunisien sur l'orientation des systèmes d'information des banques tunisiennes. Colloque CIDEGEF, University of SaintJoseph, Beyrout, Lebanon: 2829 octobre.

Taylor, E. B. (1871). Primitive Culture. Murray London.

Trompenaars, F. (1993). Riding the Waves of Culture. Nicholas Brealey Publishing, London.

Usunier, J. C. (2003). Valeurs féminines et performances économiques: une analyse crossnationale. Revue économique et sociale, 61(1), 33-46.

Rabeb Riahi is a doctor in management sciences

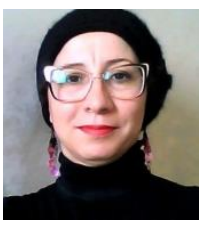
and a member of the URRED laboratory. She started teaching at the university in 2006 and attended Tunisian and French universities. She has published several research articles and participated in various international conferences. Her field of research is related to accounting, taxation, auditing, finance, intercultural management. 